\title{
Aerodynamic Optimization of Wing by Camber Morphing using Cfd
}

\author{
Rudresh M, Rohith S, Rohith T N, Darshan R, Dilip H V
}

\begin{abstract}
This paper presents the CFD analysis of the 2-Dimensional NACA0012 airfoil carried out for identifying its aerodynamic coefficients (Lift and Drag coefficients), then further implementing morphing technology on the same two-dimensional NACA0012 airfoil, again carrying out CFD analysis to determine its aerodynamic coefficients (Lift coefficient $\left(C_{L}\right)$ and Drag coefficient $\left(C_{D}\right)$, then comparing the results of both the airfoil shapes particularly to the amount of Lift generated to prove that morphing airfoil produces more amount of Lift when compared to typical airfoil shapes. Using ANSYS Design modeler airfoil geometry was created and morphing shape could be achieved by XFLR5 software further the analysis is carried out using FLUENT 18.1 at subsonic flow. This morphing enables to improve aerodynamic efficiency.
\end{abstract}

Keywords: Angle of attack, computational fluid dynamics, Co-efficient of lift, Co-efficient of drag,

\section{INTRODUCTION}

Aircraft industry is one among most expensive industries, as airlines try to control costs but the price of jet fuel was 10 per cent of the operating cost of the industry according to 2001. Presently 35 per cent of the airlines budget is consumed by the jet fuel. In order reduce the consumption of fuel one of the most suitable way is to improve the aircraft performance expanding its flight range. The flight range can be increased by reducing the amount drag imposed on aircraft during its flight and increasing the lift force. The conventional type of wings tends to produce more drag compared to morphing type wing. Morphing changes the camber of a wing smoothly which is an effective way in changing aerodynamic forces and moments produced by Wings which in turn enhances

Revised Manuscript Received on May 15, 2020.

* Correspondence Author

Dr. RUDRESH M *, Aeronautical department, Dayananda Sagar College of Engineering, Bangalore, Karnataka, India

Email: rudresh-ae@dayanandasagar.edu

ROHITH S, Aeronautical department, Dayananda Sagar College of Engineering, Bangalore, Karnataka, India

Email: contactrohiths@gmail.com

ROHITH T N, Aeronautical department, Dayananda Sagar College of Engineering, Bangalore, Karnataka, India.

Email: rohithraj198@gmail.com

DARSHAN R, Aeronautical department, Dayananda Sagar College of Engineering, Bangalore, Karnataka, India.

Email: darshanr13@gmail.com

DILIP H V, Aeronautical department, Dayananda Sagar College of Engineering, Bangalore, Karnataka, India.

Email: dilipaviator46@gmail.com

(C) The Authors. Published by Blue Eyes Intelligence Engineering and Sciences Publication (BEIESP). This is an open access article under the CC BY-NC-ND license (http://creativecommons.org/licenses/by-nc-nd/4.0/) aerodynamic performance for different flight conditions. The conventional wings are optimized for single flight condition but they tend perform poorly for other flight condition. Morphing can be the best solution for this problem as aircraft wings allows adapting shape at different conditions by this we can draw out the best performance out of this at different flight condition.

The word morphing describes the ability to change the shape of an object during its operation, in accordance to aircraft wing morphing technology the morphing types can be the (1) camber morphing (2) span morphing (3) wing sweep (4) wing twist etc. The camber morphing seems to be the best as it allows the maximum aerodynamic efficiency for a fixed span of the wing where a non-morphing wing is a compromise between the flight conditions.

\section{A. Wing terminology}

- Morphing; Morphing can be defined as the ability to undergo transformation, or to change the character of particular object. In particular to aerospace it would refer to capacity of plane's wing to change shape during flight thus providing some aerodynamic advantages

- Camber; It's the Mean line passing through the mid-section of the airfoil, i.e. from leading edge to trailing edge.

- Chord; It's the straight line passing from leading edge to trailing edge which represents the angle of wing when deployed during flight.

- Leading edge; Front most section of a wing or an airfoil which is blunt or round in shape, it allows the facing wind to flow over upper and lower surface of wing.

- Trailing edge; Rear most section of wing which is sharply shaped to allow air to join after leaving the wing. The trailing edge provides space to mount control surfaces.

\section{LITERATURE SURVEY}

[1]Nipun P Raval and his team did CFD analysis and compared with experimental data. CFD analysis is carried out on NACA0012 and evaluated for stall condition.

[2]B.K.S. Woods, O Bilgen and M.I Friswell: Work presents wind tunnel testing of the Fish Bone Active Camber morphing concept which has been proposed as a compliant morphing structure applicable to a wide range of fixed and rotary wing applications. The researchers made conclusion that, FishBAC aerofoil is capable to generate lift more than flapped aerofoil. 
[3]Ignazio Dimino, Monica Ciminello, Antonio Concilio, Andre Gratias, Martin Schuller and Rosario Pecor: presented work, which deals with the development and implementation of a morphing system made of integrated actuators and sensors, driven by a control architecture. An innovative smart configuration is achieved by the properly assembly of standard components. The adaptive trailing edge changes the global wing curvature in order to compensate the weight variation of the aircraft during cruise, as a consequence of the fuel consumption. In the same way, it can adapt the same wing camber as a function of the actual take-off weight, depending on the hosted passengers and their luggage (or the boarded goods - cargo).

[4]Mohamed A. Fouad Kandil, Abderady Okasha Elandy: This study investigates CFD analysis flow over GOE 387 airfoil at different angle of attack varying from $-5^{\circ}$ to $20^{\circ}$. They have used ANSYS Design modeler for creation of geometry and analysis is done using FLUENT 17.2. Pressure distributions over GOE 387 airfoil are presented following by the $C_{L}-C_{D}$ curves.

[5]Iman Dayyani, Haddad Khodaparast, Benjamin KS Woods and Michel Friswell: This work presents the construction material requirements of the morphing wing. As the morphing wing design is complicated since the wing needs adapt its structure at various phases of flight. The morphing wing structure also needs to perform under typical aerodynamic and structural loading

[6]Maurizio Arena, Christof Nagel, Rosario Pecora, OliverSchorsch, Antinio Concilio and Ignazio dimino : Here the author describes the adaptive structure characterization such as wing trailing edge with highly deformable skin. The main morphing part of wing is the trailing edge, which the trailing edge movement under repeated cycles while being strong enough to preserve its shape under repeated aerodynamic loadings. The analysis of this trailing part has been described.

\section{OBJECTIVE}

- The objective is to enhance aerodynamic characteristics of an airplane wing using "Morphing technology".

- To compare the results between conventional and morphed airfoil results.

- To draw out conclusion between conventional airfoil and morphed airfoil in terms of aerodynamic performance.

\section{METHODOLOGY}

\section{A. SELECTION OF AIRFOIL}

Fig. 1: NACA0012 airfoil

By detailed background study of morphing concepts and literature survey, it shows that symmetric airfoil is suitable to design the camber morphing wing so in order to compare our CFD results NACA0012 airfoil is selected as shown below.

\section{B. MODIFICATION OF SELECTED AIRFOIL}

To the above selected airfoil is morphed such that the aerodynamic characteristics are increased compared to NACA0012. XFLR5 software is used to modify the airfoil selected. Many configurations is designed and analyzed, best morphed airfoil is selected and CFD analysis is carried out. The airfoil is morphed such that the $70 \%$ of airfoil from trailing point is bending downwards. So the camber of airfoil is increased.

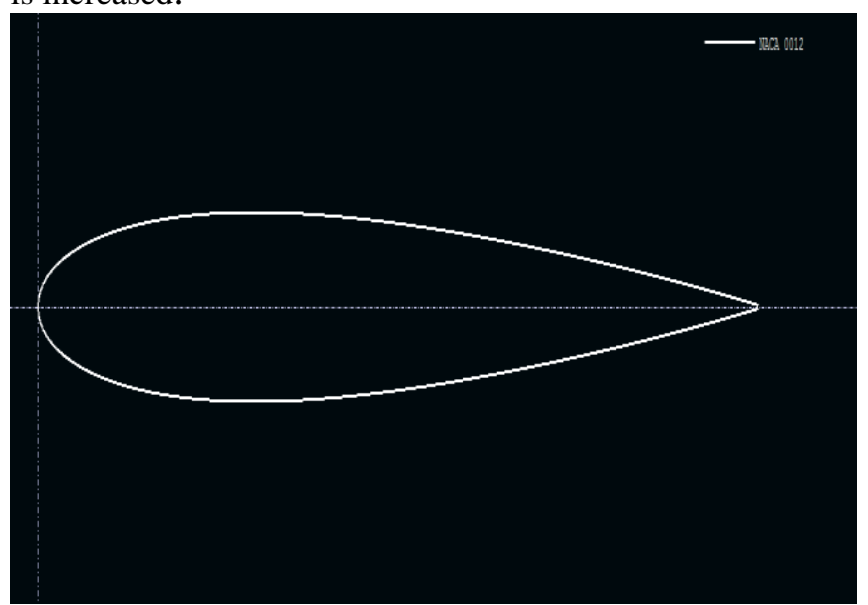

Fig. 2: NACA0012 XFLR Interface

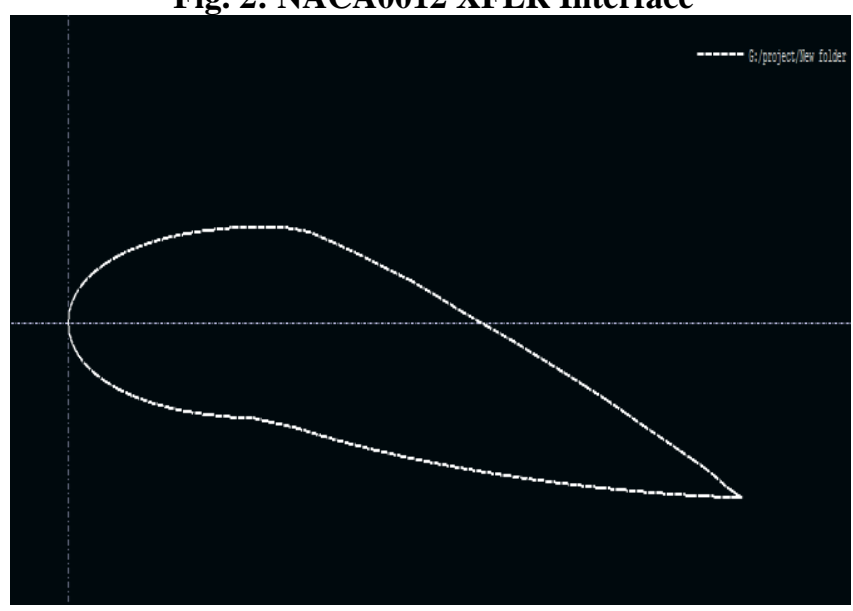

Fig. 3: Modified NACA0012 airfoil

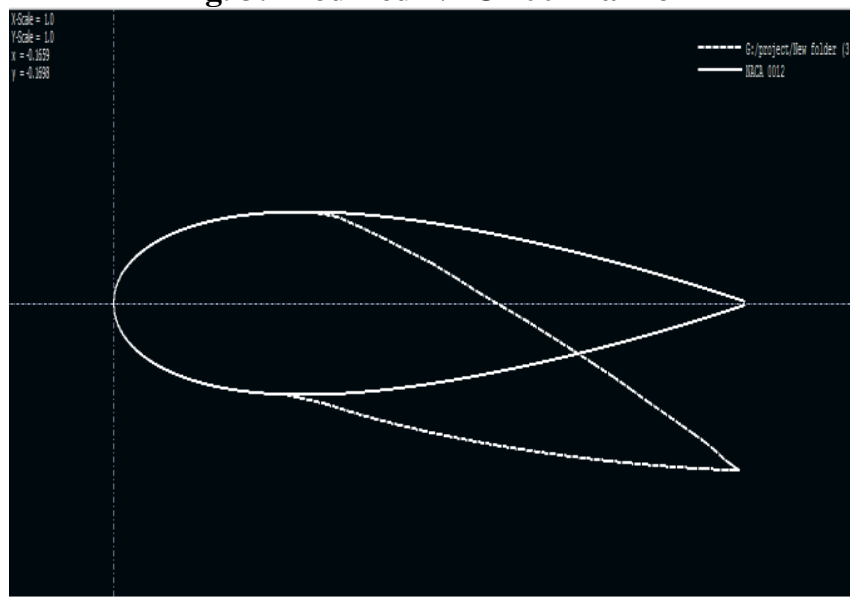

Fig. 4: Geometric comparison between NACA0012 and modified airfoil (morphed) configuration

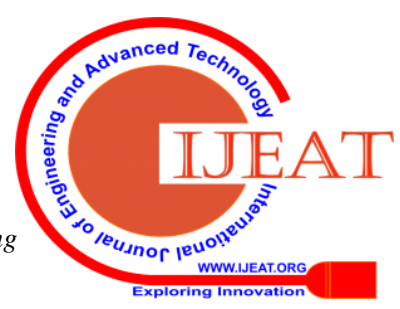




\section{RESULT AND ANALYSIS}

\section{A. Domain Setup}

The domain or flow field around the model has the inlet and far field at 15times the chord length i.e. $1000 \mathrm{~mm}$ from the leading edge of the airfoil, and the outlet is at distance of 25times the chord i.e. $25000 \mathrm{~mm}$ from the leading edge, as shown in fig. 5 . The distance between the inlet and the airfoil helps in stabilizing the flow before it reaches the model.

Meshing of the model is done using ICEM meshing tool. The mesh parameters Eriksson skewness, Aspect ratio, and Determinant are maintained within the acceptable range. . The acceptable values for aspect ratio should be less than 30 and greater than 1, values of Eriksson skewness and determinant should be less than 1 . But as our study concentrated on boundary layer the overall mesh quality doesn't affect the results so the mesh around the airfoil should be proper

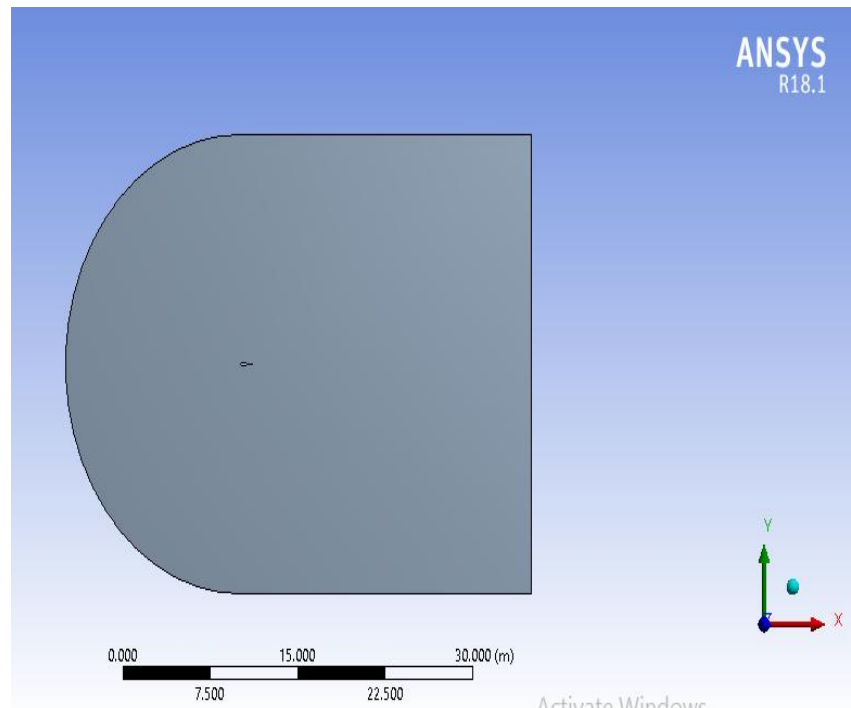

Fig. 5: Domain-NACA0012

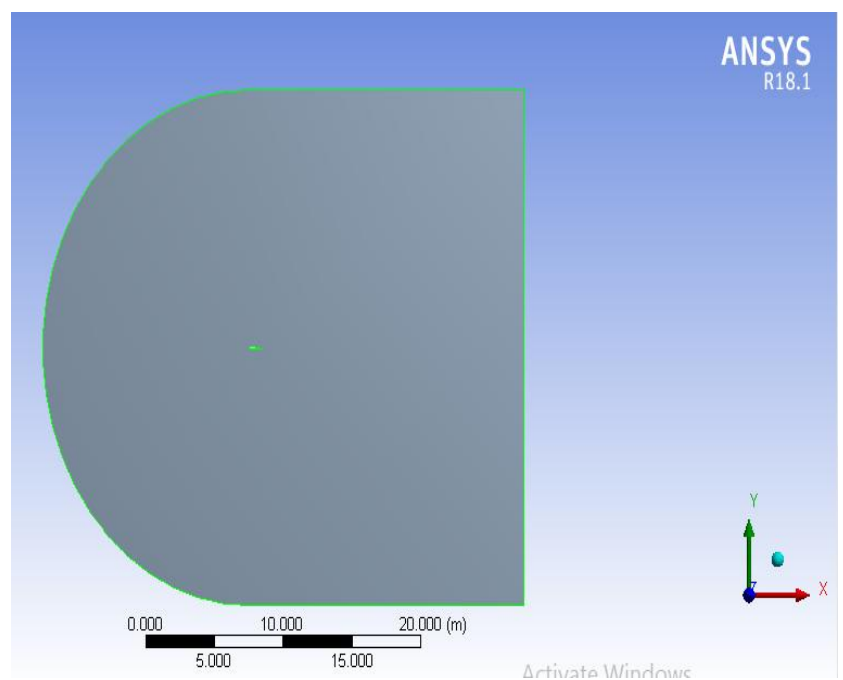

Fig. 6: Domain-Morphed airfoil

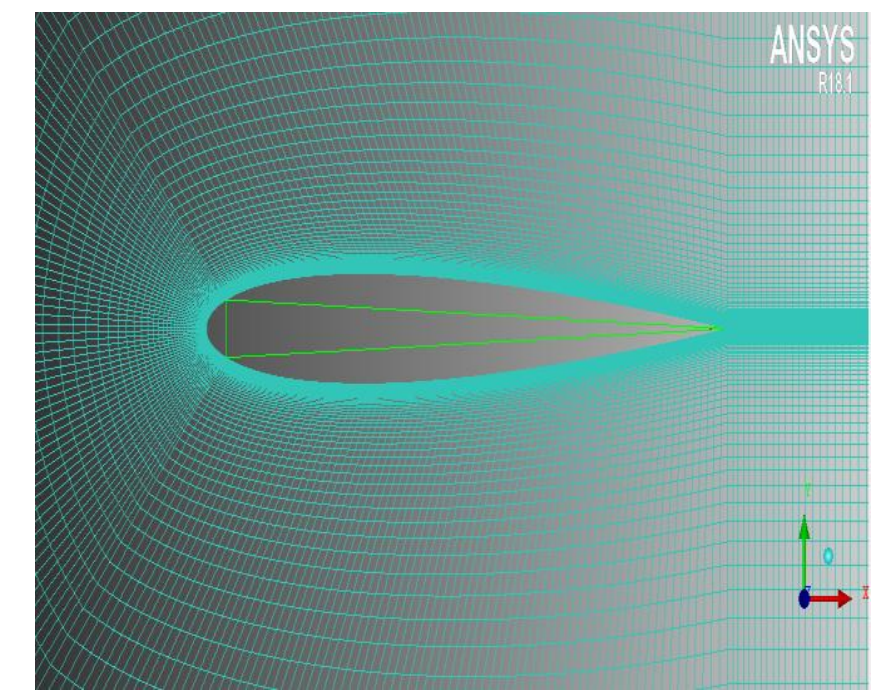

Fig. 8; Close-up Mesh domain-NACA0012

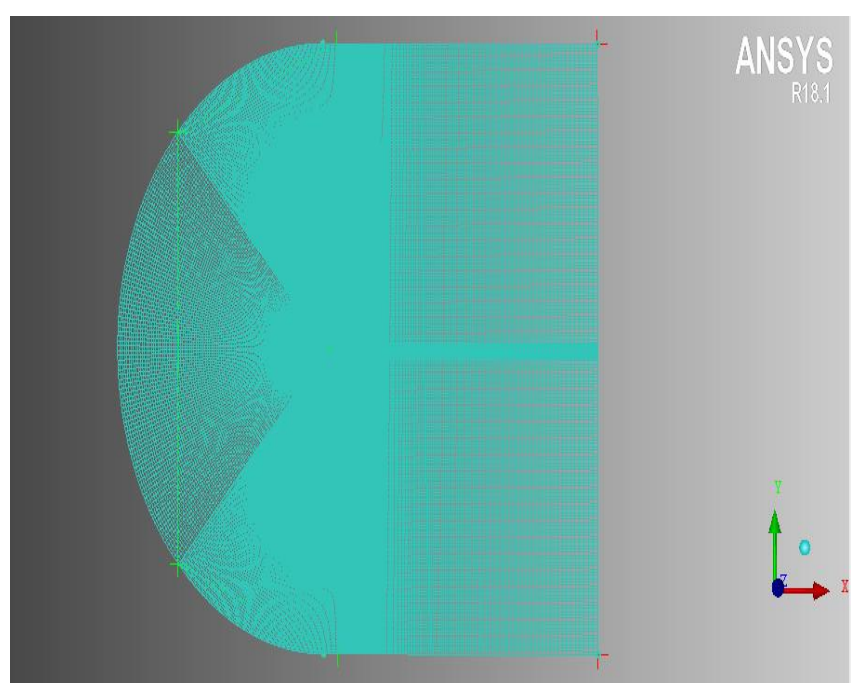

Fig. 9: Mesh domain-Morphed airfoil

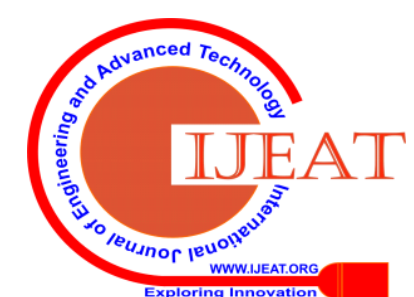




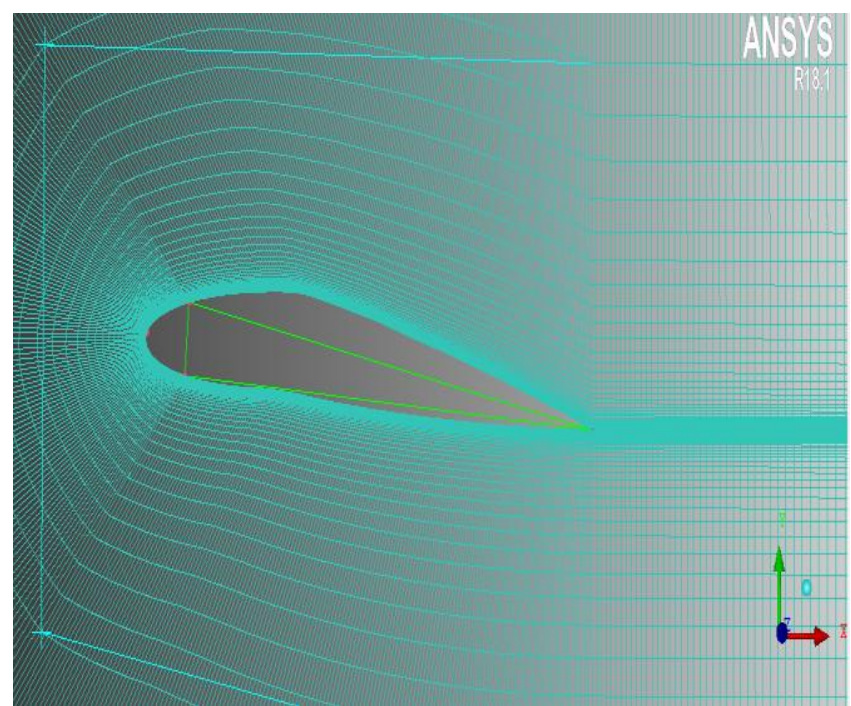

Fig. 10: Close-up Mesh domain-Morphed airfoil

\section{B. Solver selection}

For accurate simulation of flow conditions, it was necessary to select the proper solver to perform simulations in order to achieve correct solutions. Traditionally, the Pressure based solver was used for incompressible flow simulations whereas density based solver is for compressible flow simulations. The main difference between the two solvers is the way they couple the energy and momentum equations. For incompressible flows the density of fluid is independent of the temperature and hence independent of the energy equation. Hence the pressure based solver solves these two equations in a decoupled manner using SIMPLE or SIMPLER algorithms. Where in case of compressible flows the density can be related to the energy equation using the equation of state for gas. Hence the momentum and energy equations can be solved in a coupled fashion by the density based solver. The reason for selecting pressure based solver over density based is that the pressure based solver has been recently reformulated and extended to solve for compressible flows. The way how it solves the equation and how it is updated to take density effects for incompressible flow and get accurate solutions. Based on the current scope of the project which mainly requires surface pressures for the calculation of drag force, hence we chose pressure based solver over density based solver.

\section{Boundary Condition}

The domain is divided into 4 parts Far Field, Inlet, Airfoil and Outlet. In Ansys fluent setup, the inlet is taken as velocity inlet and the outlet as pressure outlet. The common boundary conditions for all the test cases are listed in table below

Table-I: Boundary conditions

\begin{tabular}{|l|l|}
\hline PARAMETERS & VALUES \\
\hline Velocity & $43.822 \mathrm{~m} / \mathrm{s}(0.128 \mathrm{Mach})$ \\
\hline Temperature & $288 \mathrm{~K}$ \\
\hline
\end{tabular}

\begin{tabular}{|l|l|}
\hline Density & $1.225 \mathrm{Kg} / \mathrm{m}^{3}$ \\
\hline Kinematic Viscosity & $0.789 \times 10^{-5} \mathrm{~m}^{2} / \mathrm{s}$ \\
\hline Y+ Value & 0.0000085 \\
\hline
\end{tabular}

\section{Computational Results and Discussion}

After considering mentioned boundary conditions analysis carried out. Data compared between NACA0012 airfoil and morphed airfoil.

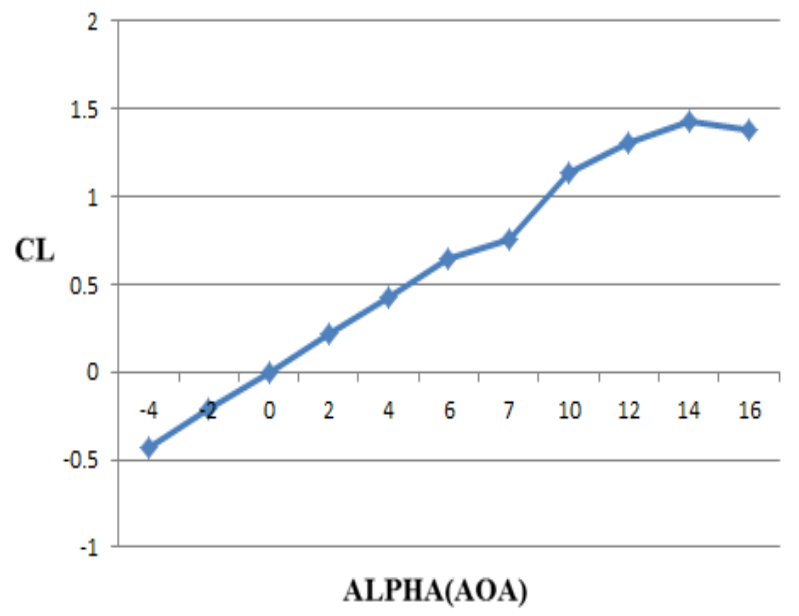

Fig. 11: $C_{L}$ v/s alpha curve-NACA0012

$\mathrm{C}_{\mathrm{L}}$ is 0.0035 at $0^{\circ}$ and reaches its maximum $\mathrm{C}_{\mathrm{L}}$ value at $14^{\circ}$ where $C_{L}$ is 1.4258 at $43.822 \mathrm{~m} / \mathrm{s}$ and $R_{e} 3 \times 10^{6}$

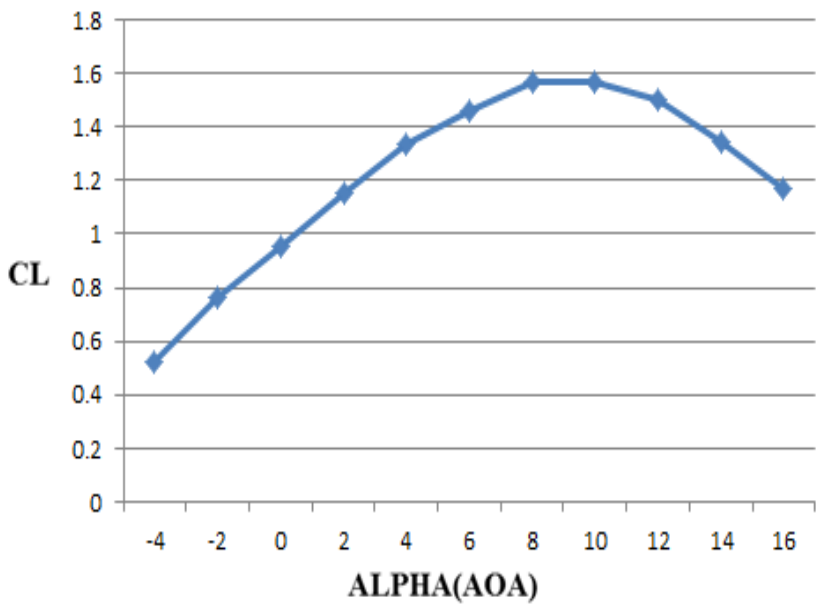

Fig. 12: $C_{L}$ v/s alpha curve-Morphed airfoil

$\mathrm{C}_{\mathrm{L}}$ is 0.9536 at $0^{\circ}$ and reaches its maximum $\mathrm{C}_{\mathrm{L}}$ value at $10^{\circ}$ where $C_{L}$ is 1.5647 at $43.822 \mathrm{~m} / \mathrm{s}$ and $R_{e} 3 \times 10^{6}$ 


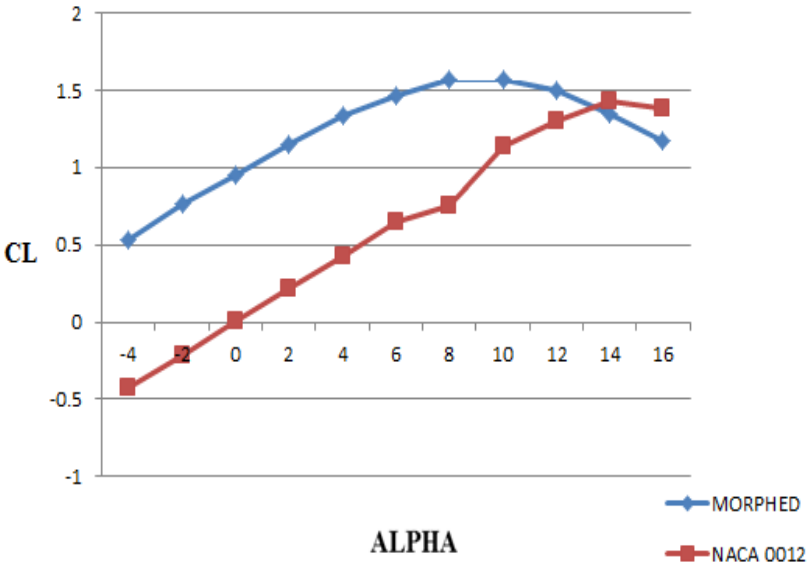

Fig. 13: Comparision of $C_{L}$ between NACA0012 and Morphed airfoil

Above graph indicates that Morphed airfoil generates more lift than NACA 0012 and at $0^{\circ}$ angle of attack morphed airfoil gives positive $C_{L}$ but NACA0012 gives negative $C_{L}$.

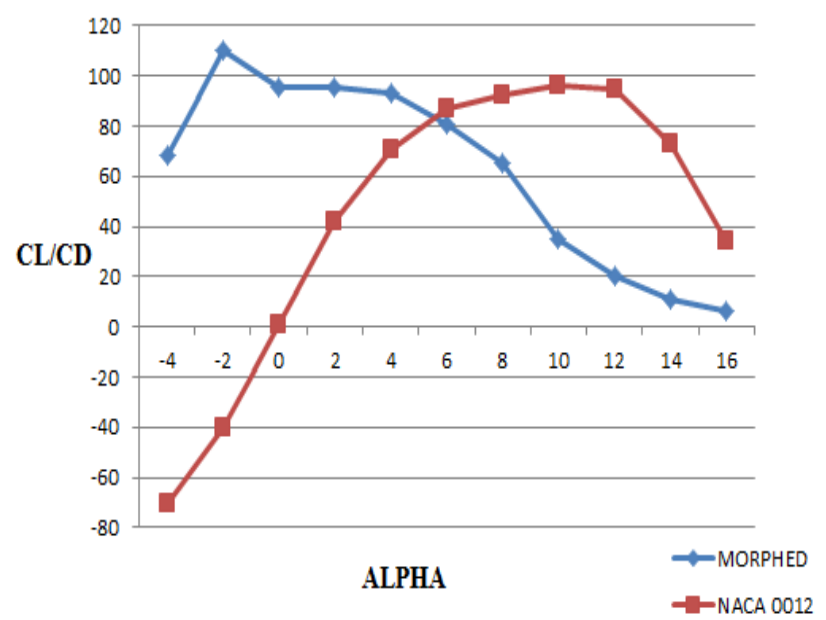

Fig. 14: Comparision of $C_{L} / C_{D}$ v/s alpha between NACA0012 and morphed airfoil

The above graph shows the stall angle of morphed airfoil is less compared to NACA 0012. Due to geomatric changes Morphed airfoil stall angle decreased even though stall angle decreses it give maximum lift at $10^{\circ}$ Angle of Attack.

E. Increment in Aerodynamic parameter

Table-II: \% increase in $\mathrm{C}_{\mathrm{L}}$

\begin{tabular}{|l|l|l|l|}
\hline AOA & $\begin{array}{l}\mathbf{C}_{\mathbf{L}} \\
\text { Of NACA 0012 } \\
\text { Airfoil }\end{array}$ & $\begin{array}{l}\mathrm{C}_{\mathbf{L}} \\
\text { Of Morphed } \\
\text { Airfoil }\end{array}$ & $\begin{array}{l}\text { \% } \\
\text { of Increment in } \\
\mathbf{C}_{\mathbf{L}}\end{array}$ \\
\hline $\mathbf{- 4}$ & 0.427 & 0.5255 & 18.74405 \\
\hline $\mathbf{- 2}$ & 0.2128 & 0.762 & 72.07349 \\
\hline $\mathbf{0}$ & 0.0035 & 0.9536 & 99.63297 \\
\hline $\mathbf{2}$ & 0.2187 & 1.151 & 80.99913 \\
\hline $\mathbf{4}$ & 0.43 & 1.3343 & 67.77336 \\
\hline
\end{tabular}

\begin{tabular}{|l|l|l|l|}
\hline $\mathbf{6}$ & 0.6428 & 1.4628 & 56.05688 \\
\hline $\mathbf{8}$ & 0.7579 & 1.5682 & 51.67071 \\
\hline $\mathbf{1 0}$ & 1.1349 & 1.5647 & 27.46852 \\
\hline $\mathbf{1 2}$ & 1.304 & 1.5012 & 13.13616 \\
\hline $\mathbf{1 4}$ & 1.4258 & 1.3413 & -6.29986 \\
\hline $\mathbf{1 6}$ & 1.3793 & 1.1714 & -17.748 \\
\hline
\end{tabular}

The above table shows the comparisons of CFD results with morphed airfoil. We can observe that the $C_{L}$ is increased at each AOA when compared to plane airfoil results. Overall the $\mathrm{C}_{\mathrm{L}}$ values are increased to $42 \%$.

\section{F. PRESSURE CONTOURS-NACA0012 AIRFOIL}

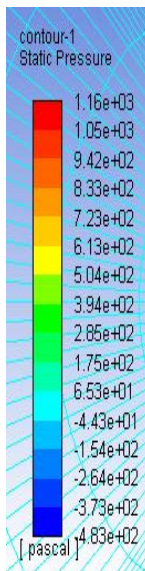

Fig. 15: Pressure contour-NACA0012 Airfoil at $0^{\circ}$ Angle of Attack

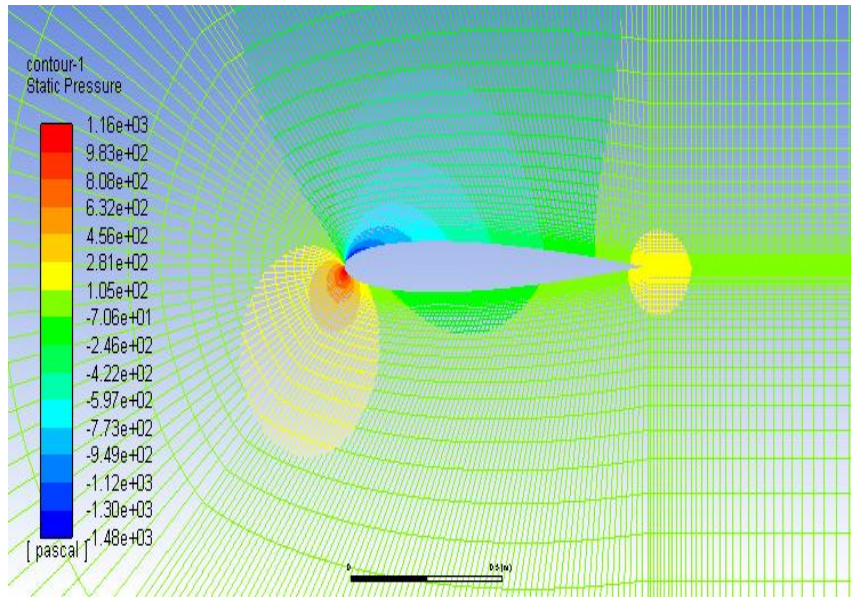

Fig. 16: Pressure contour-NACA0012 Airfoil at $4^{\circ}$ Angle of Attack

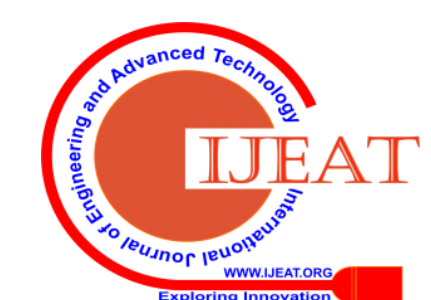




\section{Aerodynamic Optimization of Wing by Camber Morphing using Cfd}

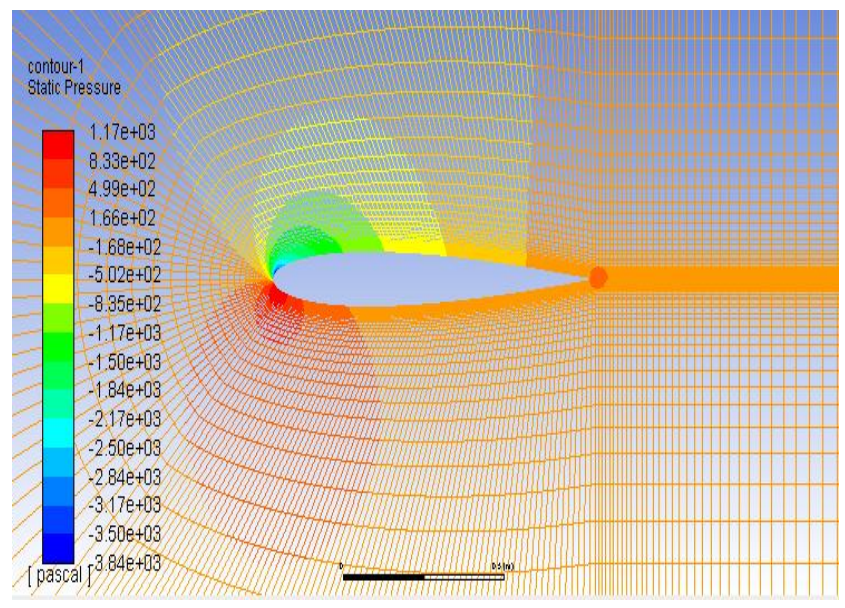

Fig. 17: Pressure contour-NACA0012 Airfoil at $8^{\circ}$ Angle of Attack

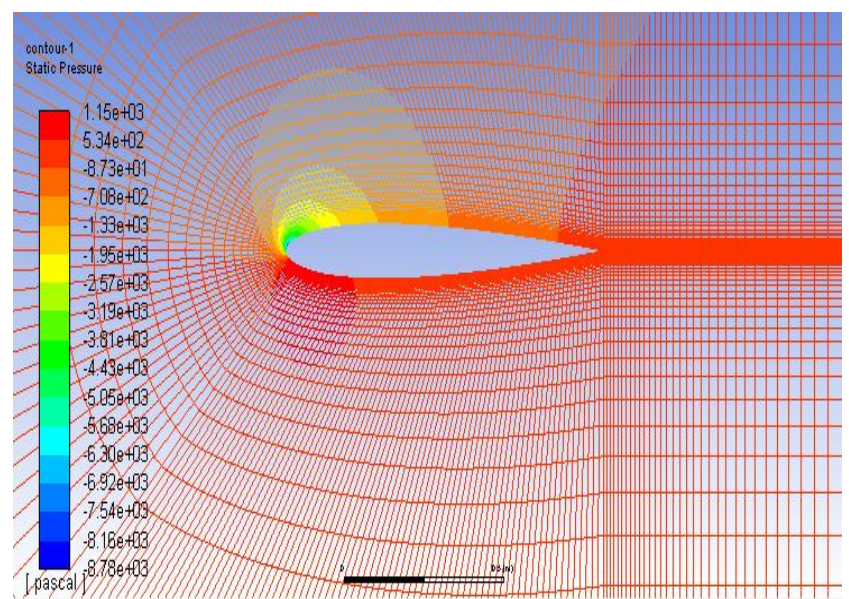

Fig. 18: Pressure contour-NACA0012 Airfoil at $12^{\circ}$ Angle of Attack

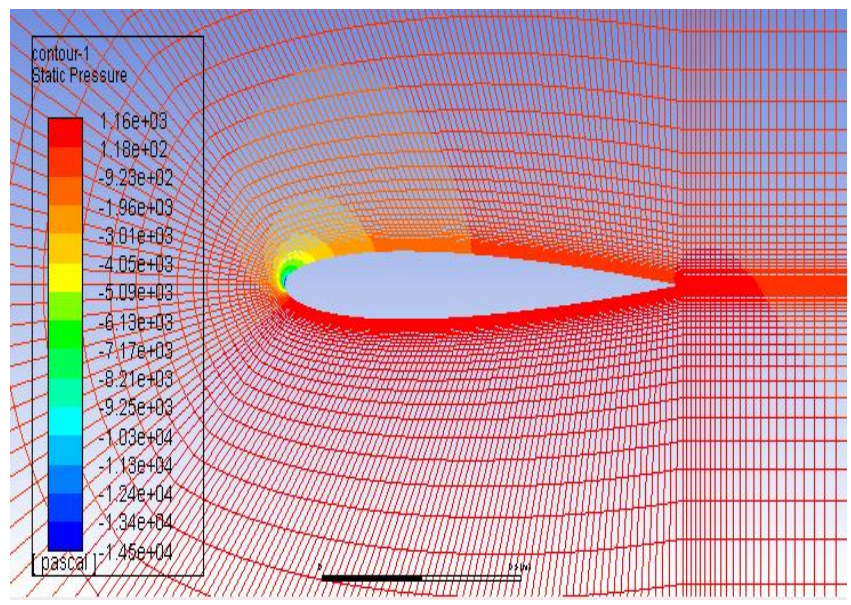

Fig. 19: Preassure contour-NACA0012 Airfoil at $16^{\circ}$ Angle of Attack

\section{G. VELOCITY CONTOURS-NACA0012 AIRFOIL}

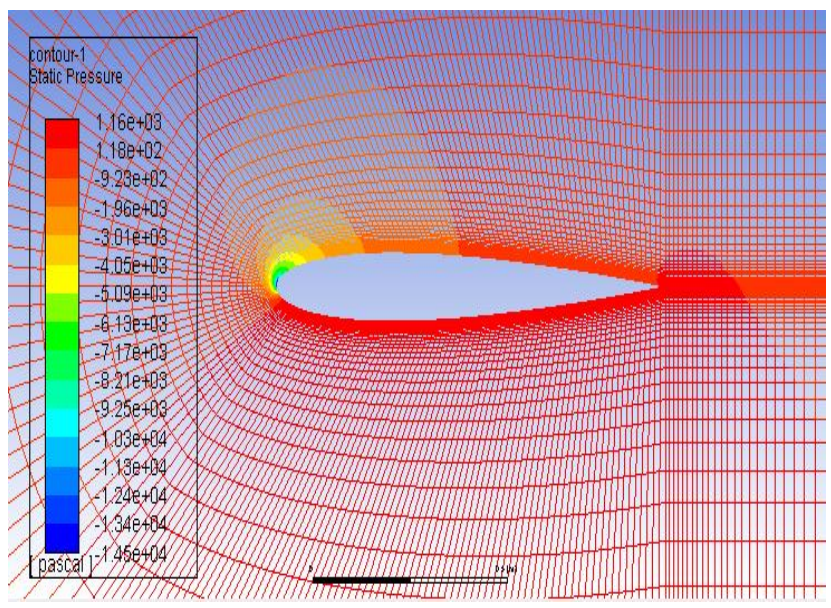

Fig. 20: Velocity contour-NACA0012 Airfoil at $0^{\circ}$ Angle of Attack

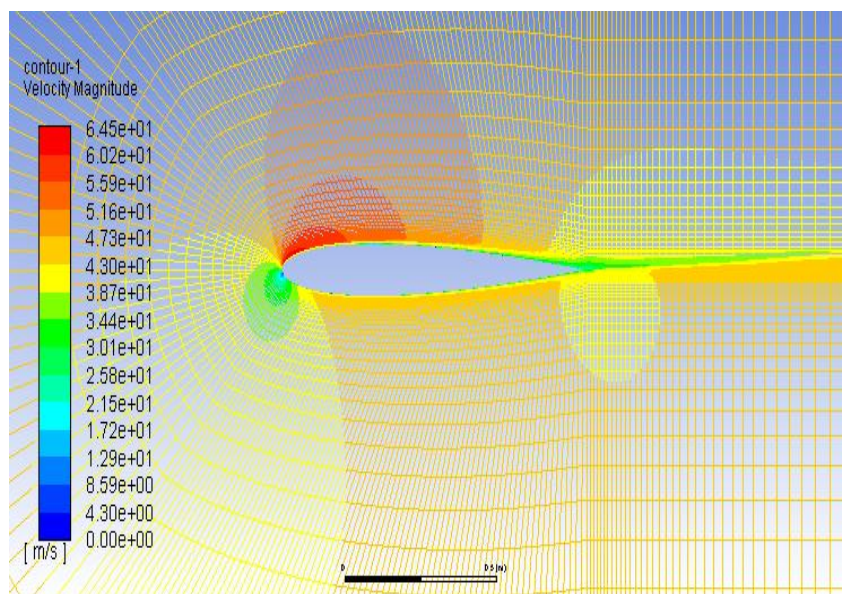

Fig. 21: Velocity contour-NACA0012 Airfoil at $4^{\circ}$ Angle of Attack

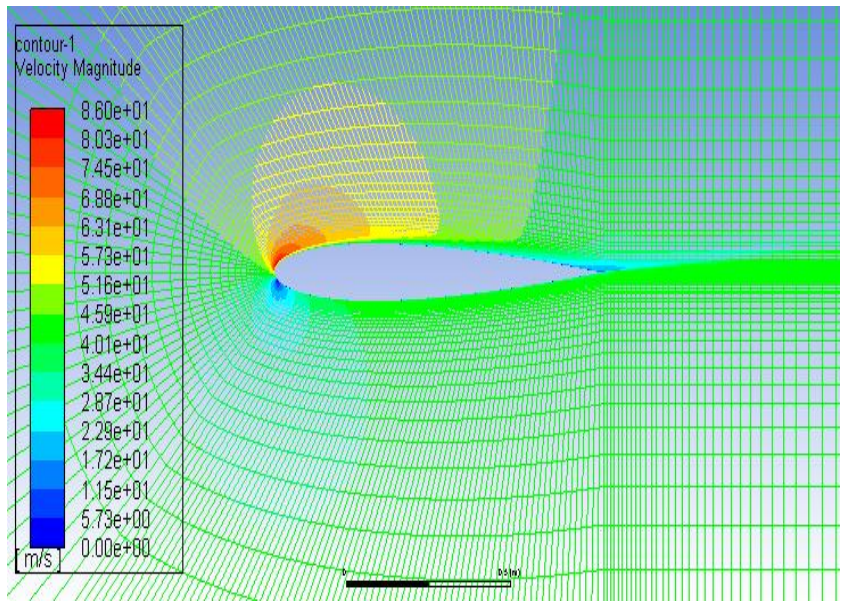

Fig. 22: Velocity contour-NACA0012 Airfoil at $8^{\circ}$ Angle of Attack

Published By:

Blue Eyes Intelligence Engineering \& Sciences Publication

(C) Copyright: All rights reserved.

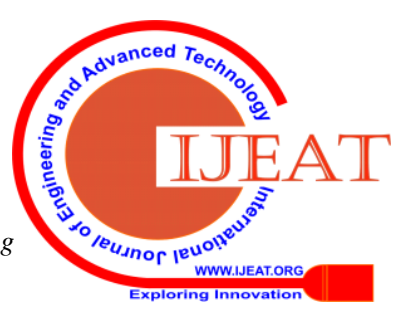




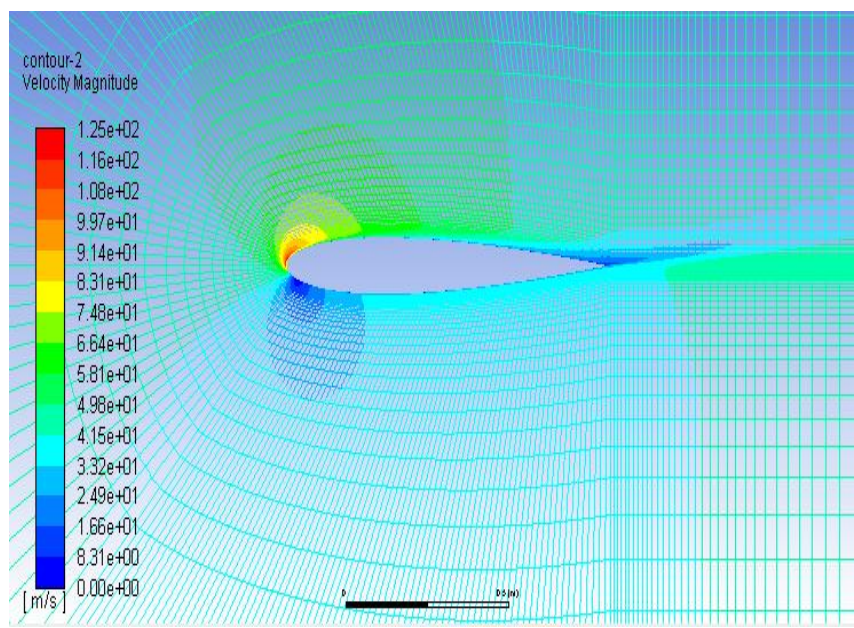

Fig. 23: Velocity contour-NACA0012 Airfoil at $12^{\circ}$ Angle of Attack

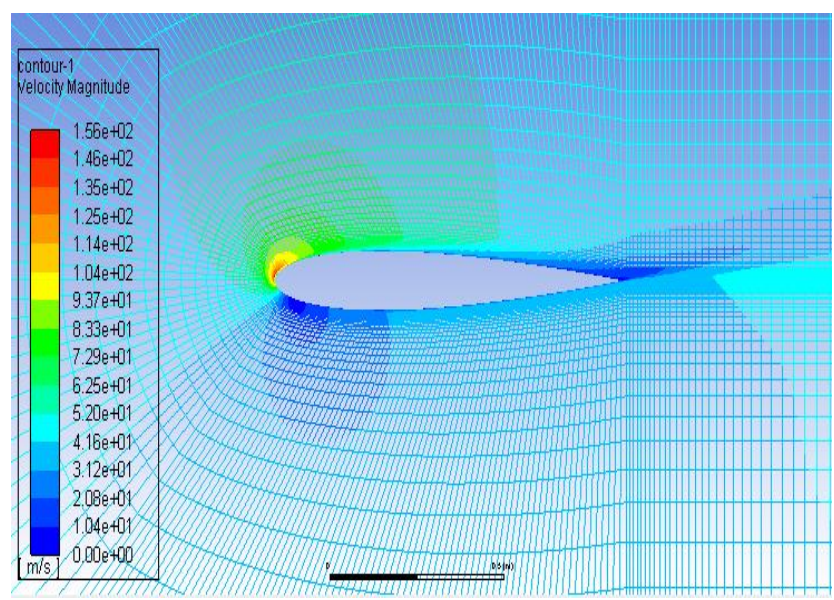

Fig. 24: Velocity contour-NACA 0012 Airfoil at $16^{\circ}$ Angle of Attack

\section{H. PRESSURE CONTOURS-MORPHED AIRFOIL}

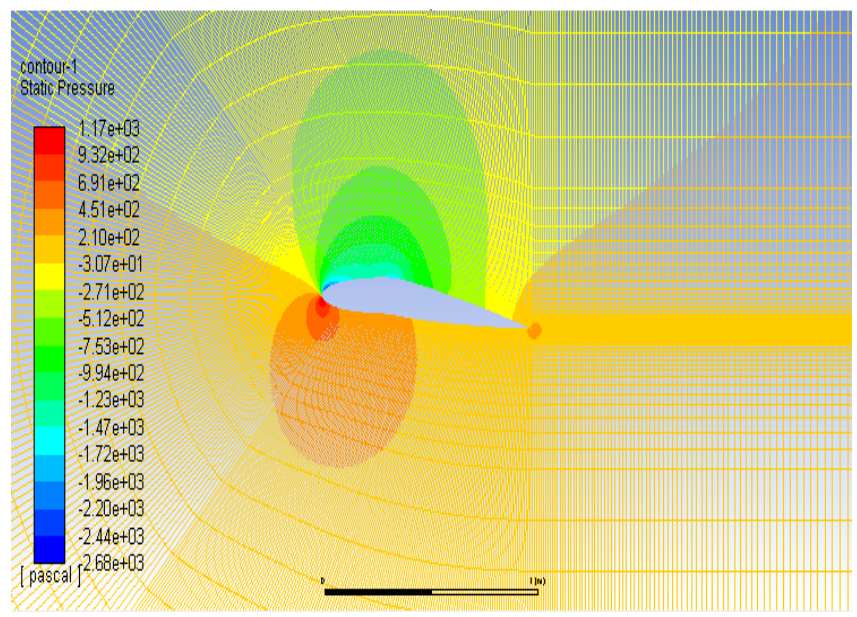

Fig. 25: Pressure contour-Morphed Airfoil at $0^{\circ}$ Angle of Attack

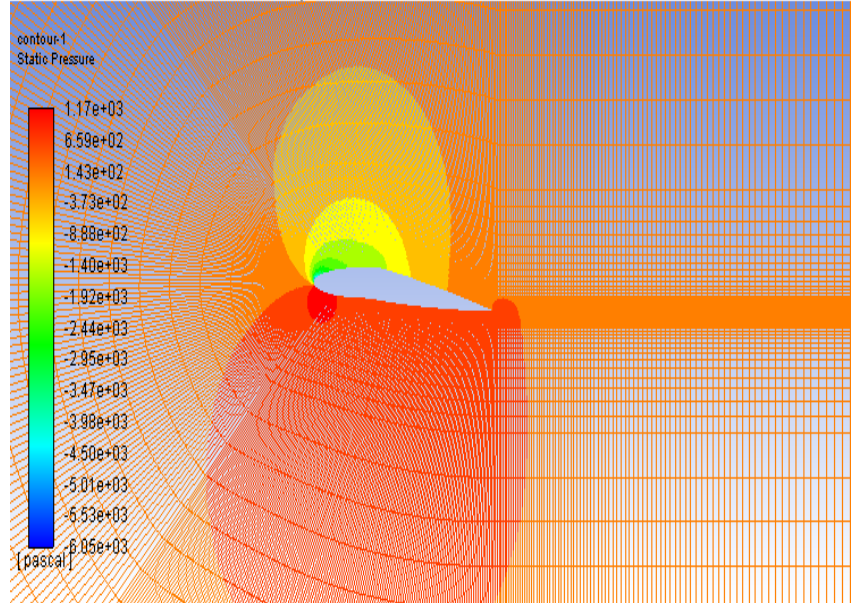

Fig. 26: Pressure contour of Morphed Airfoil at $4^{\circ}$ Angle of Attack

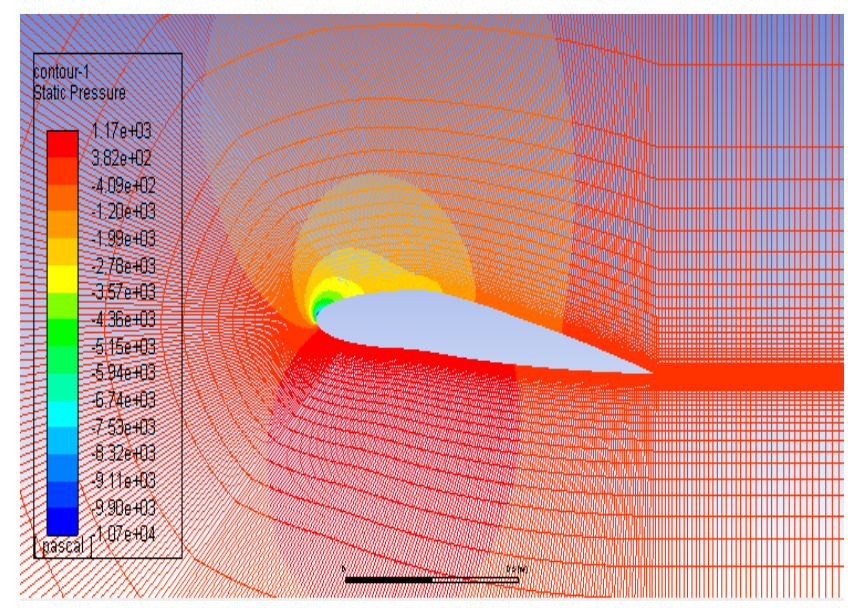

Fig. 27: Pressure contour- Morphed Airfoil at $8^{\circ}$ Angle of Attack

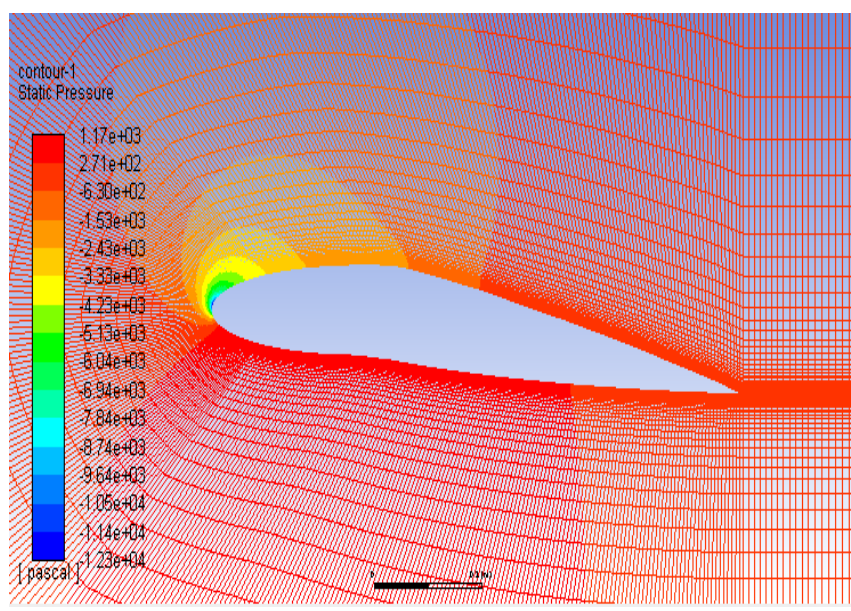

Fig. 28: Pressure contour-Morphed Airfoil at $12^{\circ}$ Angle of Attack

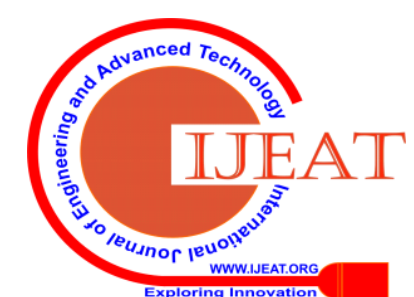




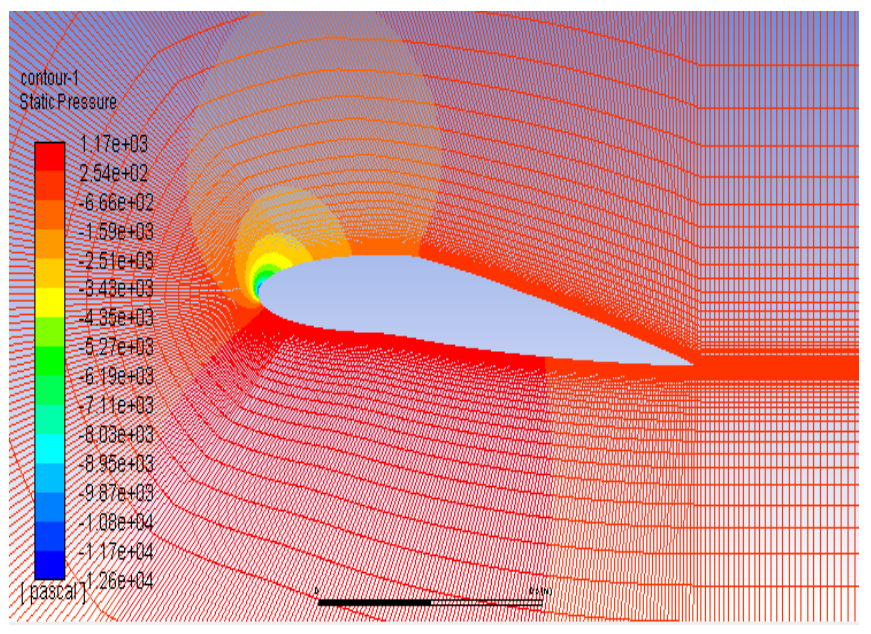

Fig. 29: Pressure contour-Morphed Airfoil at $16^{\circ}$ Angle of Attack

\section{VELOCITY CONTOURS-MORPHED AIRFOIL}

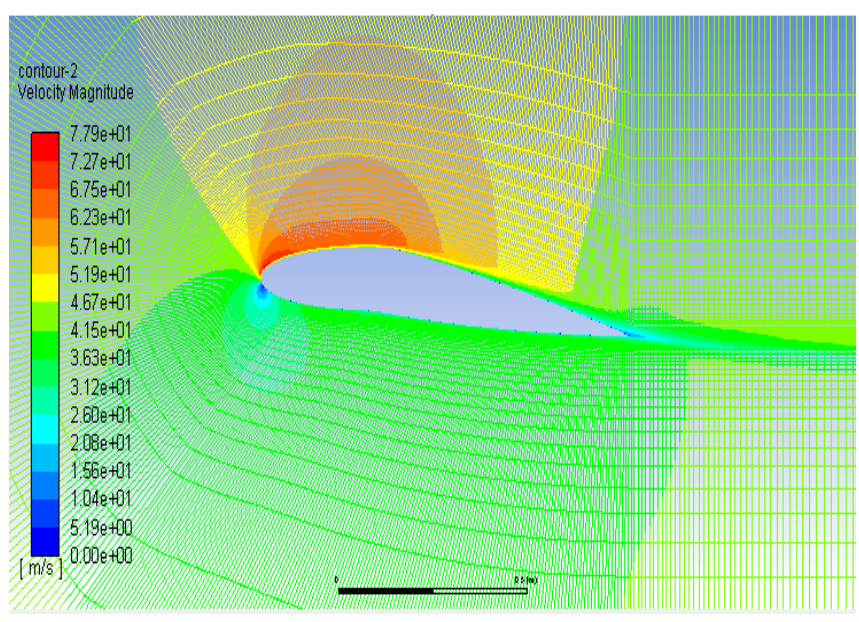

Fig. 30: Velocity contour-Morphed Airfoil at $0^{\circ}$ Angle of Attack

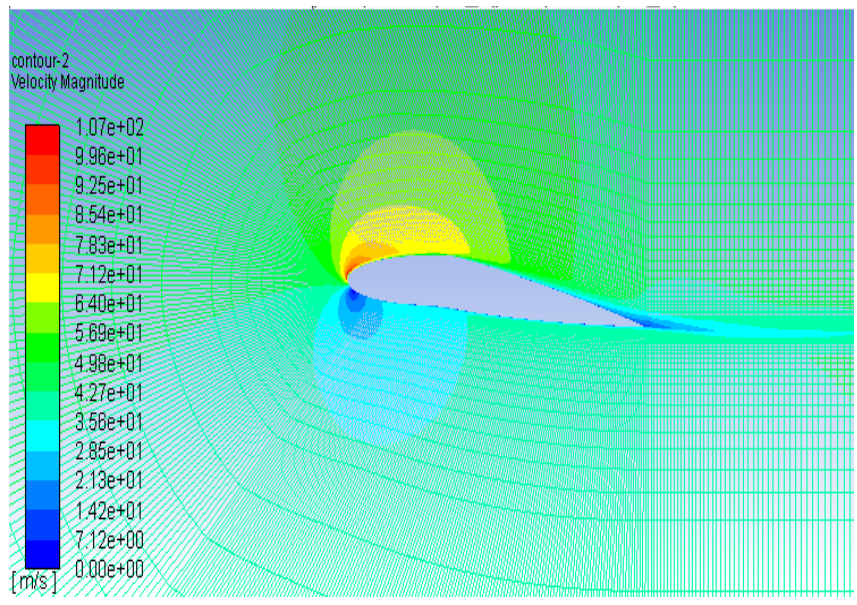

Fig. 31: Velocity contour-Morphed Airfoil at $4^{\circ}$ Angle of Attack

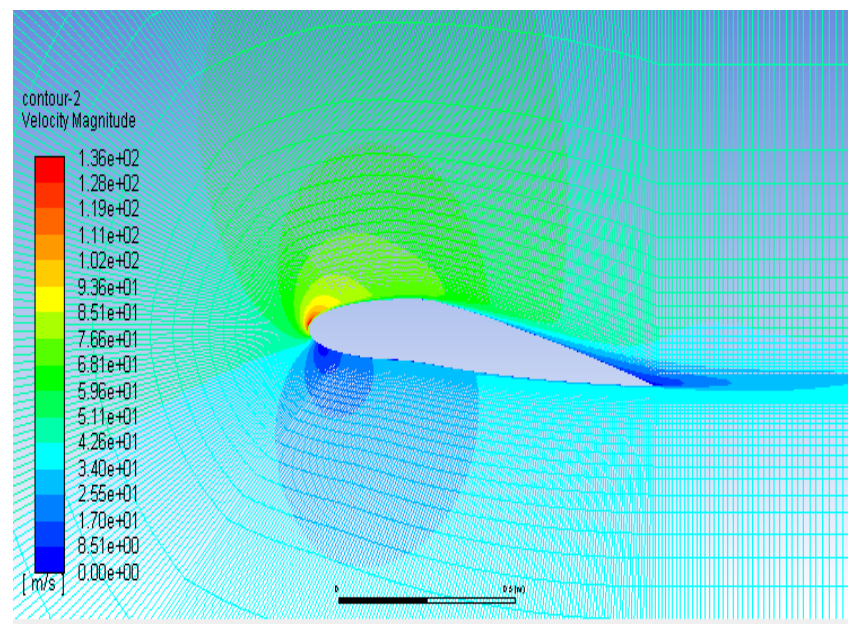

Fig. 32: Velocity contour-Morphed Airfoil at $8^{\circ}$ Angle of Attack

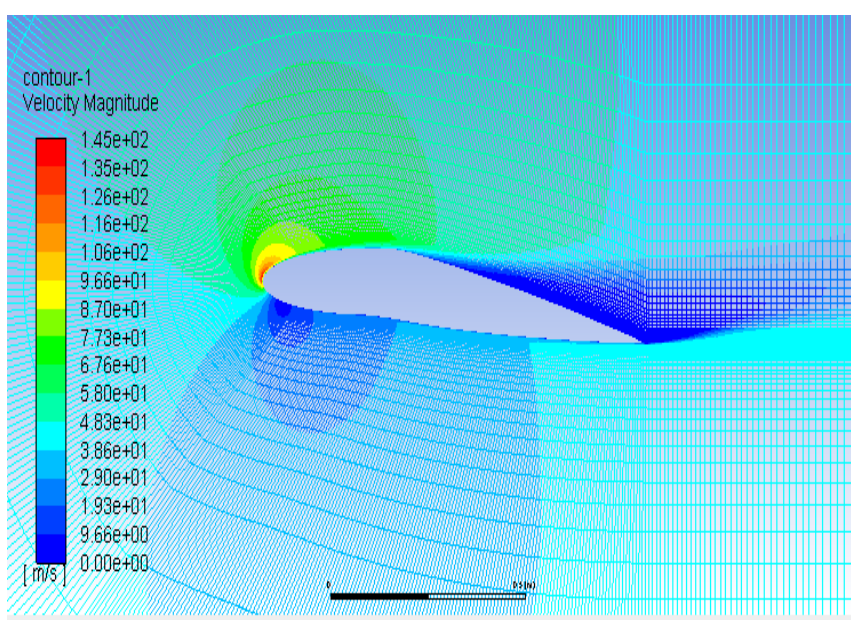

Fig. 33: Velocity contour- Morphed Airfoil at $12^{\circ}$ Angle of Attack

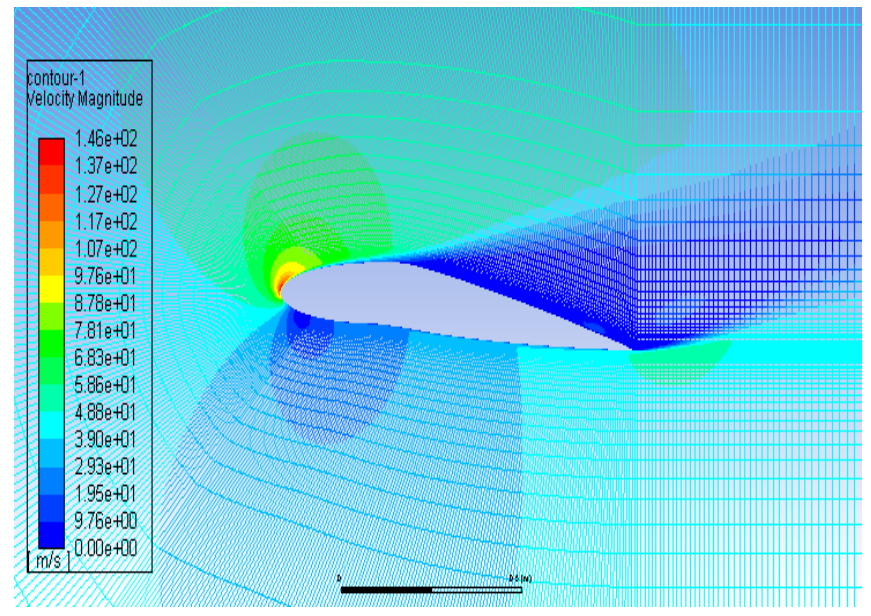

Fig. 34: Velocity contour-Morphed Airfoil at $14^{\circ}$ Angle of Attack

From the pressure and velocity contours we can observe that at 0 degree AOA the velocity on upper surface is more and pressure is less. As the AOA increases the velocity increased on upper surface and more pressure on lower surface and when AOA decreased the pressure on upper surface increases as says in theory.

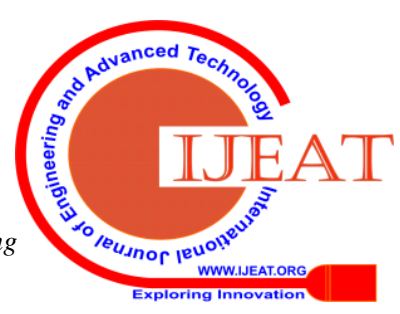




\section{OVEALL DISCUSSION:}

The CFD analysis is matched with Standard experimental Results as show in Table-2 for NACA 0012 airfoil configuration. The selected airfoil is modified and analyzed computationally to have better aerodynamic results. The CFD results obtained after modifications are compared with basic airfoil. Morphed airfoil has higher $\mathrm{C}_{\mathrm{L}}$ value than NACA 0012 airfoil, it can be seen in Table-2 that as lift increases drag is also increasing gradually which decreases the stall angle of the wing which can be the drawback of Morphing airfoil. But comparing the lift to drag (L/D) ratio of NACA0012 airfoil the morphed airfoil L/D ratio is more which is advantageous.

\section{CONCLUSION}

Thus by analyzing both conventional and morphing wing, our project results shows that Morphing wing is one of the most effective way to increase aerodynamic characteristics $\left(C_{L}, C_{D}\right)$ of a wing, they improves aircraft performance expanding its flight range by reducing drag. The morphing wing replaces conventional control surfaces for flight control thereby improving performance and stealth capability. Morphing wing reduce the weight of aircraft thereby reducing operating cost and time to repair or reconfigure.

By our results, typical conventional wing produces almost $\mathbf{0}$ lift at zero angle of attack, but the morphed wing is capable of producing $\mathbf{C}_{\mathbf{L}}$ almost equal to $\mathbf{1}$ at zero angle of attack itself.

The maximum lift $\left(\mathrm{C}_{\mathrm{Lmax}}\right)$ that can be obtained by conventional wing $\mathbf{C}_{\mathbf{L m a x}}=\mathbf{1 . 4 2}$ at $14^{\circ} \mathrm{AoA}$, but morphing wing gives $\mathbf{C}_{\mathbf{L m a x}}=\mathbf{1 . 5 6}$ at $10^{\circ} \mathrm{AoA}$ itself, which clearly depicts that implementing morphing technique on conventional wing is beneficial in various ways as mentioned above.

\section{REFERENCES}

1. Nipun P Raval, Mehta Malay, Lalani Jitesh “ CFD Analysis of NACA0012 Aerofoil and Evaluation of Stall Condition," IJETSR ISSN 2394 - 3386 Volume 4, Issue 4 April 2017

2. B.K.S.Woods, O Bilgen and M.I. Friswell., ICAST2012 \#54 "Wind Tunnel Testing of fishbone active camber morphing concept" , $23^{\text {rd }}$ International Conference on Adaptive Structures sand Technologies October 11-13, 2012, Nanjing, China

3. IgnazioDimino, Monica Ciminello, Antonio Concilio, Andre Grantis, Martin Schuller and Rosario Pecora, Spring International Publishing Swisterland 2017 DOI 10.1007/978-3-319-44507-6_9. 'WING DESIGN' by Mohammad Sadrey, Daniel Webster College.

4. J.H.S. Fincham, M.I.Friswell, "Aerodynamic optimization of camber morphing aerofoi l(2013)'”.

5. Liyana Kharulaman, Abdul Aabid, Fharukh Ahmed Ghasi Mehabobabali, Sher Afgan Khan, "Research on flows for NACA2412 Airfoil using Computational fluid Dynamics Method", International journal of Engineering And Advanced Technology, ISSN: 2249-8958, Volume-9 Issue-1, October 2019.

6. Mohamed A. Fouad kandil, Abdelrady Okasha Elandy, "Performance of GOE-387 Airfoil Using CFD", International Journal of Aerospace 2017,5(1):1-7, DOI: 10.5923/j.aerospace.20170501.01

\section{AUTHORS PROFILE}

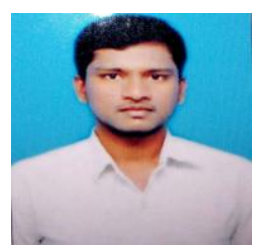

Rohith $\mathbf{S}$ is a final year Aeronautical Engg student at Dayananda Sagar College of Engineering, Bangalore. He also holds Diploma in Aeronautics from Acharya Polytechnic. He has successfully completed his In- Plant training at Hindustan Aeronautics limited Bangalore. His projects include Drone design and fabrication,
Vented airfoil design. His particular interests are UAV's, Propulsion systems, Aero modeling.

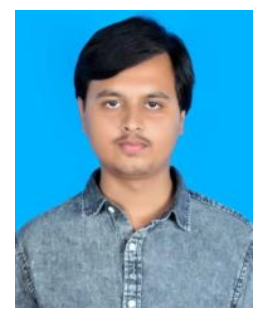

Rohith $\mathbf{T}$ N is a final year student in Bachelor of Engineering in Aeronautical Engineering from Dayananda Sagar College of Engineering, Bangalore, Karnataka. He has successfully completed his In-Plant training at Hindustan Aeronautics Limited Bangalore. Many of his Mini projects include Drone design and Fabrication, UAV design and making of virtual Rocket model. His research interests is in Aero modeling, Avionics and CFD analysis

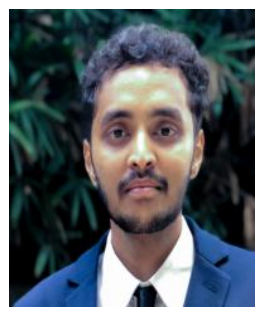

Darshan R, a final year Aeronautical Engineering student at Dayananda Sagar College of Engineering, Bangalore. He also holds a Diploma is Aeronautics and with a particular interest in Aerodynamics and Fluid mechanics.

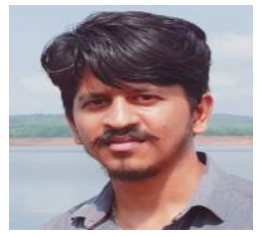

Dilip HV, currently pursuing aeronautical engineering final semester at Dayananda Sagar College Engineering, Bangalore. His interests are in the field of aviation sector, and defense.

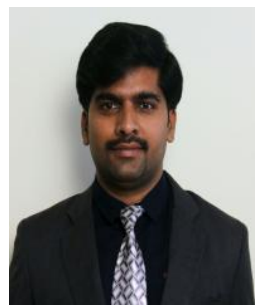

Dr. Rudresh $\mathbf{M}$ is an assistant professor at Dayananda Sagar Engineering College and has nine years of work experience. He did $\mathrm{BE}$ (mechanical), M.Tech (engineering design). Ph.D (mechanical). He has written numerous articles and reviews in international conferences and journals. He has written several books on "Finite Element Analysis", "Cab roof optimization design", "Split Blade design and development". 